\title{
Práticas de agroindustrialização e arranjos produtivos locais como estratégia de diversificar e fortalecer $a$ agricultura familiar no Rio Grande do Sul
}

\author{
Mirian Fabiane Dickel Strate \\ Fundação Agrícola Teutonia - Teutonia - Rio Grande do Sul - Brasil \\ Marcelo Antonio Conterato \\ Universidade Federal do Rio Grande do Sul - Porto Alegre - Rio Grande do Sul - \\ Brasil
}

\begin{abstract}
Resumo
A fragilidade no acesso aos mercados monopolizados, por parte dos agricultores familiares, impulsiona a procura por novos processos e práticas que emergem paralelamente aos grandes impérios alimentares. Neste contexto surgem novos mercados, que coexistem com os circuitos comerciais como as feiras, mercados integrados ao turismo, agroindústrias familiares e os institucionais, criando novos circuitos mercantis. O objetivo deste trabalho foi analisar como os arranjos produtivos locais podem fomentar a diversificação da agricultura familiar, relocalizando a produção de alimentos, através das cadeias curtas, estimulando a heterogeneidade e promovendo o desenvolvimento rural. A pesquisa foi realizada a partir do Arranjo Produtivo Agroindústria familiar, estrutura de governança que impulsiona a instalação, regularização e associativismo de agroindústrias no Vale do Taquari, RS. A metodologia utilizada foi a análise documental e entrevista aos gestores do APL Agroindústria e aos proprietários de agroindústrias integrantes do APL. Como resultado pode-se observar que as Políticas públicas de fomento para a implementação e fortalecimento dos APLs, constituem-se estratégias que podem fortalecer a agricultura familiar, promovendo a construção e o acesso a novos mercados, a criação e o desenvolvimento de novos produtos, promovendo a sucessão rural, diversificando as atividades produtivas, gerando renda, através de novos arranjos sociais e estruturas de governança horizontalizadas.
\end{abstract}

Palavras-chave: Agroindústrias. Mercados. Arranjos produtivos. 


\title{
Practices of agroindustrialization and local productive arrangements as a strategy to diversify and strengthen family agriculture In Rio Grande do Sul
}

\begin{abstract}
The fragility of farmers' access to monopolized markets drives the search for new processes and practices that emerge parallel to the great food empires. In this context, new markets emerge, which coexist with the existing commercial circuits, such as fairs, integrated markets for tourism, family agroindustries and institutional ones, creating new market circuits. The objective of this work was to analyze how local productive arrangements can foster diversification of family agriculture, relocating food production through short chains, stimulating heterogeneity and promoting rural development. The research was carried out from APL Agroindústria, governance structure that drives the installation, regularization and associativism of agroindustries in Vale do Taquari, RS; the methodology used was the documentary analysis and interview to APL Agroindústria's managers and APL's agroindustry owners. Public policies to promote the implementation and strengthening of APLs constitute strategies that can strengthen family agriculture, promoting the construction and access to new markets, creating and developing new products, promoting rural succession, diversifying activities productive, generating income, through new social arrangements and horizontal structures of governance.
\end{abstract}

Key-words: Agroindustries. Markets. Productive arrangements.

\section{Prácticas de agroindustrialización y arranjos productivos locales como estrategia de diversificar y fortalecer la agricultura familiar en el Río Grande del Sur}

\section{Resumen}

La fragilidad en el acceso a los mercados monopolizados por parte de los agricultores familiares impulsa la búsqueda de nuevos procesos y prácticas que emergen paralelamente a los grandes imperios alimentarios. En este contexto surgen nuevos mercados, que coexisten con los circuitos comerciales como las ferias, mercados integrados al turismo, agroindustrias familiares e institucionales, creando nuevos circuitos mercantiles. El objetivo de este trabajo fue analizar cómo los arreglos productivos locales pueden fomentar la diversificación de la agricultura familiar, reubicando la producción de alimentos, a través de las cadenas cortas, estimulando la heterogeneidad y promoviendo el desarrollo rural. La investigación fue realizada a partir del Arreglo Productivo Agroindustria familiar, estructura de gobernanza que impulsa la instalación, regularización y asociativismo de agroindustrias en el Valle del Taquari, RS. La metodología utilizada fue el análisis documental y entrevista a los gestores del APL Agroindustria ya los propietarios de agroindustrias integrantes del APL. Como resultado se puede observar que las Políticas públicas de fomento para la implementación y fortalecimiento de los APLs, se constituyen estrategias que pueden fortalecer la agricultura familiar, promoviendo la construcción y el acceso a nuevos mercados, la creación y el desarrollo de nuevos productos, promoviendo la sucesión rural, diversificando las actividades productivas, generando ingresos, a través de nuevos arreglos sociales y estructuras de gobernanza horizontalizadas.

Palabras clave: Agroindustrias. Mercados. Arreglos productivos.

\section{Introdução}

Alimentos nos conectam com o ambiente, com a economia, com a saúde, além de conectar entre si uma rede de pessoas, da produção ao consumo. Comer é mais que ingerir alimentos, compreende as relações pessoais, sociais, culturais, econômicas e políticas que estão envolvidas no ato de alimentar-se. Se somos o que 
comemos, temos que nossa identidade se define pelo que comemos, mas também como comemos, onde e com quem comemos (MENASCHE, 2015, p. 4). Para a autora os saberes e as práticas da alimentação são entendidos como um patrimônio cultural, de grupos sociais específicos inseridos em seu território.

O território rural do Vale do Taquari apresenta uma grande diversidade de paisagens e recursos naturais, heterogeneidade na organização das estruturas produtivas, diversidade étnica, cultural e múltiplas formas de organização social. A agricultura familiar tem um papel fundamental para o desenvolvimento da região, a diversidade de saberes e práticas desenvolvidas pelas populações no uso dos recursos naturais deram origem a estratégias de desenvolvimento bastante heterogêneas, de grande potencial de geração de renda, uso da mão de obra, organização social e política.

Este artigo aborda a diversificação da agricultura familiar frente à inserção em novos mercados, a partir dos arranjos produtivos locais, instituídos através de políticas públicas, uma estrutura de cooperação e governança que impulsiona a instalação, regularização e integração de agroindústrias no Vale do Taquari. A pesquisa combinou aspectos quantitativos e qualitativos. O caráter quantitativo é expresso pela mensuração e análise de diversas variáveis, obtidas de fontes primárias e secundárias, combinando a pesquisa bibliográfica, a pesquisa documental e a pesquisa de campo. A pesquisa bibliográfica e documental foi adotada para, a partir de dados quantitativos, caracterizar a região estudada e compreender a dinâmica da agricultura no Vale do Taquari. Os dados foram obtidos através do IBGE, Censo agropecuário de 2006, FEE, CODEVAT, AMTURVALES e CODETER, Plano Territorial de Desenvolvimento Rural Sustentável. O caráter qualitativo foi desenvolvido através de entrevistas semiestruturadas e observação participante, com proprietários de três agroindústrias integrantes do arranjo produtivo e junto aos gestores do APL Agroindústria Vale do Taquari.

\section{Práticas de agroindustrialização como estratégia de desenvolvimento rural}

Para Giddens (1984, p. 2) “As práticas persistem no espaço e no tempo”. Dessa forma, elas nunca são inteiramente estáticas: eles emergem, permanecem, mudam e desaparecem.

As práticas sociais interagem para formar conjuntos de práticas que organizam o espaço-tempo da vida social. (SCHATZKI, 2001). Em algumas situações, elas competem por recursos, incluindo aqueles do tempo e da energia das pessoas. Elas também podem apoiar e manter-se mutuamente, por exemplo, comer depende da preparação dos alimentos. Assim, as práticas se conectam e, ao fazê-lo, formam sistemas complexos que têm uma espécie de vida própria. Schatzki (2005) apresenta que a vida social é formada por um nexo de práticas humanas e arranjos materiais, que possibilitam o seu desenvolvimento.

Schatzki (2001) sugere que as conexões entre as práticas podem ser harmoniosas ou conflitivas. Então, embora algumas práticas possam ser incompatíveis, outras se tornam tão próximos que dependem uma da outra, o que significa que conjuntos completos de práticas são reproduzidos rotineiramente. Outra dica de intervenção é prestar atenção às formas em que os conjuntos de 
práticas co-evoluem com uma visão para fortalecer ou enfraquecer as conexões entre elas.

A agroindústria familiar rural é uma forma de organização onde a família transforma a matéria-prima oriunda da pequena propriedade em alimentos visando à agregação de valor ${ }^{1}$. A atividade agroindustrial não se constitui uma novidade para os agricultores familiares; faz parte da sua própria história e da sua cultura, essa atividade emerge como uma prática alicerçada no seu conhecimento histórico, melhorando as suas maneiras de fazer e de produzir, ajustando e culminando com a agroindustrialização. Para Woortmann e Woortmann (1997), é a lógica do "saber fazer" camponês, que por sua vez, pode revelar um modelo integrado de apreensão do mundo e das coisas. As ações dos camponeses se orientam a partir do "saber fazer" e na possibilidade de sua continuidade.

Como definiu Mior (2005), a agroindústria familiar rural é uma forma de organização em que a família rural produz, processa elou transforma parte de sua produção agrícola elou pecuária, visando, sobretudo, à produção de valor de troca que se realiza na comercialização, ou seja, o agricultor deixa de ser um mero produtor de mercadorias. Os produtos são comercializados diretamente ao consumidor em cadeias curtas, feiras, eventos comerciais, roteiros turísticos com visitação às propriedades, merenda escolar e mercados locais. Segundo o autor, no princípio os produtos processados eram destinados para o consumo da família e, em menor grau, para as trocas estabelecidas entre os agricultores. Com a reestruturação dos mercados a partir das mudanças nos hábitos de consumo, a agroindustrialização familiar que estava vinculada com uma economia de subsistência passa a se encontrar inserida nos mercados locais, nacionais e internacionais, o que permite acumular e reproduzir recursos dentro da agricultura familiar a partir da comercialização de produtos processados.

As tendências recentes do sistema agroalimentar, segundo Maluf (2004), caracterizam-se pela coexistência de processos de padronização e de diferenciação no consumo dos alimentos, cujos reflexos repercutem até a etapa da produção agrícola. De um lado, assiste-se à continuidade da concentração do processamento agroindustrial para fazer frente aos requisitos da produção em grande escala, ainda que as novas tecnologias permitam que a maior escala de produção seja acompanhada da diferenciação dos produtos finais. Por outro lado, a valorização dos produtos com atributos diferenciados de qualidade cria novas oportunidades de mercado, muitas das quais, acessíveis aosagricultores de pequeno e médio porte.

Wilkinson (2003) afirma que a condição de ser visto como "pequeno" passa a ser considerada cada vez mais como uma vantagem estratégica na medida em que é associada à tradição, à natureza, ao artesanal e ao local, um conjunto de valores agora premiado pelo mercado consumidor. Assim, a possibilidade de novos padrões de qualidade, associado ao artesanal, ao familiar e a valores ambientais, e a certificação desses valores por selos de garantia passa a ser um excelente instrumento para

\footnotetext{
${ }^{1}$ O conceito de agregação de valor a um produto reflete a busca pela diferenciação, ou seja, sua "descomoditização". O agricultor procura sair da situação de tomador de preços e tenta, dentro de certos limites, impor o seu preço ao produto, de acordo com a sua política mercadológica e relação com toda a dinâmica da concorrência, desejos dos consumidores e ainda da análise final do consumidor sobre o custo-benefício que acaba por autorregular todos os preços e atividades econômicas.
} 
construção social dos novos mercados para agricultura familiar. Mesmo assim, neste cenário a agricultura familiar é obrigada a atender uma série de padrões de produção que pretendem garantir a qualidade dos produtos ou como expressa Wilkinson (2003):

[...] ao aludir sobre o resgate da imagem tradicional de 'pequeno produtor' "como estratégia de mercado, exige tanto uma reinvenção de tradições como a adoção de práticas novas, a medida em que estas tradições agora tenham como aval um exigente consumidor urbano". (WILKINSON, 2003, p. 05).

Entre as formas de organização espacial baseadas na proximidade entre agricultores e consumidores encontramos os Sistemas Agroalimentares Localizados (SIAL). Eles podem ser definidos como "organizações de produção e de serviços (unidades de produção agrícolas, empresas agroalimentares, comerciais, de serviço...) associadas por suas características e seu funcionamento em um território específico" (CIRAD, 1996). Mais do que uma simples forma de organização o SIAL demonstra que a territorialização da produção não se limita à indústria tradicional ou àquela da inovação, ela pode apresentar características próprias, sintetizadas por Pecqueur (2009, p. 85), apud Muchnik (2002):

a função de identidade particular dos bens alimentares: são os únicos a não serem usados, mas incorporados, no sentido próprio, pelos consumidores. A especificidade da matéria-prima viva, perecível, heterogênea e por natureza sazonal. A ligação com as características do meio e a gestão dos recursos naturais. O saber-fazer e as competências mobilizadas, tanto na etapa da produção, quanto nas etapas da transformação e do consumo dos produtos.

A singularidade do produto está imersa em um sistema de valores e práticas específicas, pois quanto mais escasso ele é no mercado pela distinção de suas qualidades e proveniência, mais valorizado será. O desenvolvimento de redes alimentares alternativas está remodelando o espaço rural através da criação de nichos e de novas estruturas organizacionais espaciais e redes que competem com os sistemas produtivos mais padronizados, estabelecidos no setor convencional. (SONNINO; MARSDEN, 2017, p. 122).

Novos padrões de relações de consumo se desenvolveram e prosperaram simultaneamente em diversos países com diferentes nuances e suscitaram diferentes formas de Políticas Públicas. Iniciativas como programas de articulação da gastronomia regional com produtos típicos e as compras governamentais de produtos locais são novas referências em produção e consumo. Na velocidade destas transformações, o conceito de "cadeias curtas" tem abrigado diversas formulações e valorizações destas novas relações.

No sentido de reconhecer a importância da produção tradicional, Sonnino e Marsden (2017) consideram que estratégias de valorização e legitimação de práticas tradicionais e/ou artesanais são capazes de promover a relocalização dos alimentos; associando qualidade à pequena produção, práticas tradicionais, paisagens, natureza e recursos locais. Para Cruz e Schneider(2010), emmuitas áreas rurais brasileiras, a produção e a comercialização de produtos tradicionais, apreciados pela população e 
por turistas, têm contribuído para a revalorização da condição de agricultores e para a manutenção das famílias no meio rural. A atual valorização dos alimentos tradicionais, vinculados aos locais de origem, tem desafiado o sistema agroalimentar moderno.

As cadeias agroalimentares curtas remetem a formasde comercialização da produção agrícola que busca a proximidade entre produtores e consumidores, possibilitando uma conexão que permita maior interatividade na construção mútua de relações de confiança. Essas cadeias se caracterizam por enraizar práticas alimentares em relações eco sociais locais, estabelecendo novas relações mercantis. De acordo com Marsden et al. (2000), há três tipos principais de cadeias curtas Short Food Supply Chains (SFSC): as de face-a-face; de proximidade espacial e espacialmente estendida. Elas também podem ser classificadas ou caracterizadas por critérios de qualidade, em regionais / artesanais e ecológico-naturais. As cadeias face a face caracterizam-se pelas vendas diretas do produtor ao consumidor por meio de feiras, vendas em domicílio, casas coloniais e rotas de turismo. O segundo tipo, o de proximidade espacial, se faz por meio de vendas a varejistas locais, restaurantes, vendas institucionais por meio da merenda escolar, mercados regionais, casas coloniais e eventos nos municípios. O terceiro tipo de cadeias curtas, a espacialmente estendida, compreende casos que envolvem fair trade e certificação de indicação geográfica

Para SCHNEIDER (2004, p. 96), “O desenvolvimento rural seria uma tentativa de reconstrução das bases econômicas, sociais e ambientais, e das próprias unidades familiares, em face das limitações e lacunas intrínsecas do paradigma produtivista". É necessário planejar a reconstrução analisando todo o contexto que gira em diferentes aspectos tanto na sociedade como na economia. Ademais, nesta abordagem, destaca-se o papel dos agricultores, que passam a orientar suas práticas produtivas, não mais segundo o padrão agricultor- empresário profissional, mas, crescentemente, para o modelo de um agricultor- camponês, que é autônomo, domina tecnologias, toma decisões, controla e gestiona processos, enfim, decide sobre seu modo de viver e trabalhar nos marcos de uma sociedade capitalista.

A atividade agroindustrial não se constitui uma novidade para os agricultores familiares, faz parte da sua própria história e da sua cultura, essa atividade emerge como uma prática alicerçada no seu conhecimento histórico, melhorando as suas maneiras de fazer e de produzir, culminando com a agroindustrialização. A busca por alimentos saudáveis e alicerçados na herança cultural, bem como o contato com a natureza e o meio rural de uma sociedade cada vez mais urbana, dá visibilidade aos produtos com atributos diferenciados de qualidade, criando novas oportunidades de mercado, muitas das quais acessíveis aos agricultores familiares.

\section{Agricultura familiar do Vale do Taquari - RS}

A agricultura familiar que emergiu na região do Vale do Taquari, a partir da diversidade de povos e culturas, indígenas, imigrantes açorianos, portugueses, alemães e italianos, dedicou-se à policultura e à pecuária de pequena escala, baseado na produção para o autoconsumo, mas vendendo o excedente a comerciantes que atendiam ao mercado de consumo da capital, facilitado pela proximidade geográfica. Conforme Berold, Grisel, Schmitz (2007), a produção para autoconsumo era 
composta de carnes bovina, suína e de aves, leite, banha, ovos, farinhas de trigo e milho, raízes comestíveis e frutas (mandioca, batata-doce e frutas cítricas), além de algumas leguminosas, como feijões e lentilhas. Inicialmente dedicaram-se à policultura e à pecuária de pequena escala, sobretudo para atender ao mercado de consumo da capital facilitado pela proximidade geográfica. Além do "ouro branco" das colônias (banha suína), o rol de artigos era amplo. Segundo Ahlert e Gedoz (2001), entre 1900 e 1916, em Estrela, existiam alambiques, curtumes, cervejarias, destilarias, refinarias de banha, serrarias, moinhos, engenhos de arroz e produção de azeite, salsichas, refrigerantes, sabão, arame, vassouras, etc. A maioria destes produtos eram processados por pequenas agroindústrias, queijarias, moinhos e destilarias.

O sistema colonial contemporâneo foi marcado pela ampliação da produção de excedentes agrícolas (em especial de suínos, derivados de leite, produtos coloniais diversos, etc.) e de uma maior inserção no mercado. No entanto, a limitação das superfícies agrícolas disponíveis e o aumento da população acarretaram uma crise no sistema de cultivo com tração animal leve e geraram um êxodo rural dos agricultores e de seus descendentes para novas regiões de colonização. Cabe salientar que esse período é fortemente marcado por uma importante diferenciação socioeconômica no âmbito da agricultura de cunho familiar, ocorre a formação e consolidação de um segmento de agricultores familiares capitalizados e fortemente tecnificados.

No Vale do Taquari, o complexo agroalimentar destaca-se pela produção de leite, frangos e suínos, cenário onde às cooperativas agropecuárias têm se destacado pelo sistema de integração, constituindo mercados sólidos para os agricultores. As cooperativas agroindustriais caracterizam-se pela associação de agricultores, geralmente com base cultural comum, que se reúne sob um arcabouço organizacional e institucional próprio, voltado especialmente para ganhos de escala e poder perante os clientes.

A simplificação dos sistemas de culturas, a especialização e intensificação produtiva que levam a perda de autonomia das famílias, conferindo-Ihes uma posição subordinada e cada vez mais vulnerável em relação ao mercado. No entanto, paralelo a produção para os mercados, as práticas de produção para o autoconsumo e agroindustrialização, herança cultural, continuaram presentes na cultura do território. Em momentos de crise do sistema hegemônico ou estímulo para a diversificação, através de políticas públicas de valorização destas práticas, eles emergem enquanto contra- movimentos e constituem estratégias de desenvolvimento.

A agricultura familiar tem um papel fundamental para o desenvolvimento do território, a diversidade de saberes e práticas desenvolvidos pelas populações no uso dos recursos naturais, deu origem a estratégias de desenvolvimento bastante heterogêneas, de grande potencial de geração de renda, uso da mão de obra, organização social e política. 
Figura 1 - Mapa do Vale Do Taquari- RS
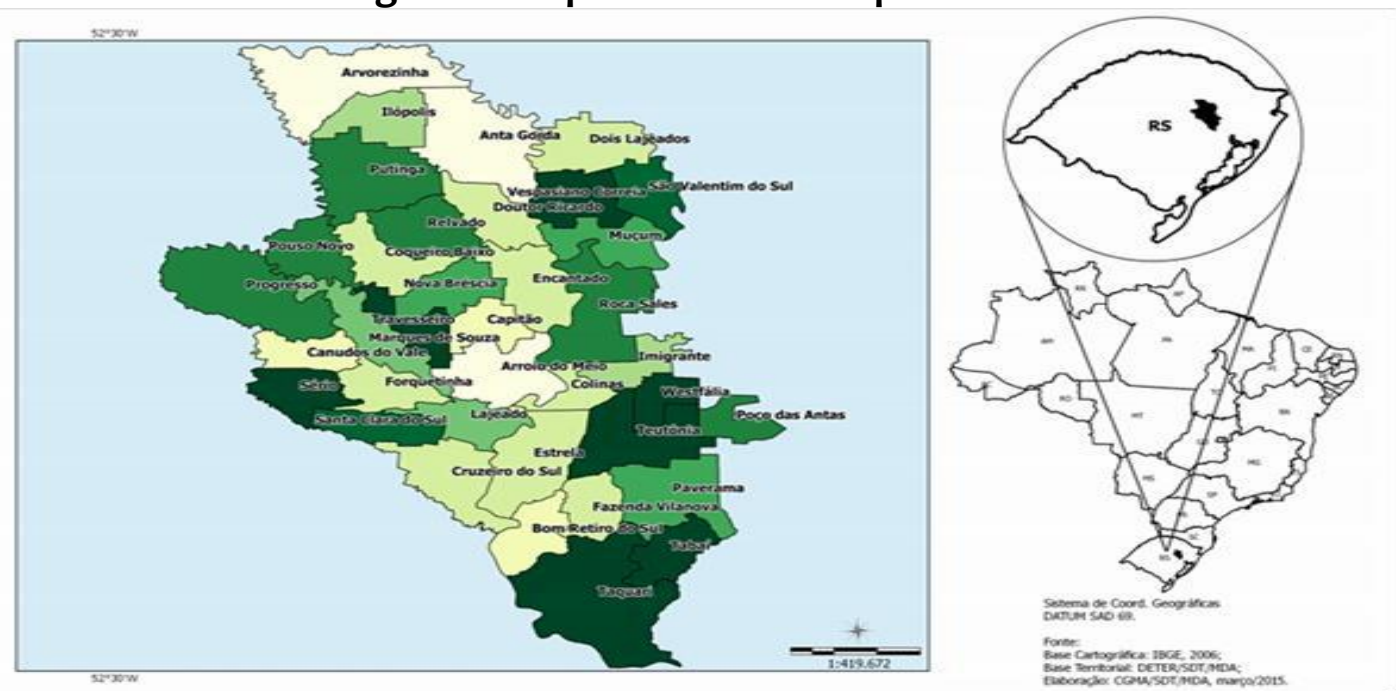

Fonte: Kolchinski et al., 2017

O Vale do Taquari encontra-se na região central do estado do Rio Grande do Sul, distante média $150 \mathrm{~km}$ de Porto Alegre, tem 4.916,58 ${ }^{2}$ de área (1,71\% da área do estado) e conta com 355.418 habitantes (3,07\% do estado - Censo demográfico 2010). Conforme Kolchinski et al., (2017) a população rural do Vale do Taquari, com 87.153 habitantes(2013) corresponde a $26,42 \%$ da população do território que tem sua base econômica e social alicerçada na pequena produção rural com de 24.067 estabelecimentos da agricultura familiar, representando 93,9\% do total de estabelecimentos, bem superior à média do Estado que corresponde a 14,9\%. Neste contexto 60.787 pessoas são ocupadas pela agricultura familiar, demonstrando a sua importância para geração de renda.

\section{Quadro 1 - Caracterização da agricultura familiar do território Vale do Taquari e}

2015

\begin{tabular}{|l|c|}
\hline \multicolumn{1}{|c|}{ Variável } & Valor \\
\hline Área $\left(\mathrm{Km}^{2}\right)$ & $4.916,58$ \\
\hline Pop total (hab) (2015) & 355.418 \\
\hline Pop urbana (hab)(2013) & 242.738 \\
\hline Pop rural (hab) (2013) & 87.153 \\
\hline $\mathrm{N}^{\circ}$ de estabelecimentos da agricultura familiar & 24.067 \\
\hline Pessoal ocupado na agricultura familiar & 60.787 \\
\hline
\end{tabular}

Fonte: Kolchinski et al., 2017 
A urbanização do território acentuou-se após 1990, a população urbana do Vale do Taquari cresceu 18,93\% quando comparados os dados do Censo do IBGE de 2000 e 2010, sendo que do Estado aumentou em 9,41\%, os dados também revelam que o Vale do Taquari perdeu 11,10\% de sua população rural, no mesmo período.

A economia local representa $3,2 \%$ do total do Produto Interno Bruto (PIB) gaúcho. Em 2013, o município de Lajeado, foi considerado o município mais desenvolvido do RS, $13^{\circ}$ mais desenvolvido do país, segundo o Índice Firjan de Desenvolvimento Municipal (IFDM), atingindo 0,8813 . A produção de alimentos constitui-se uma das principais atividades econômicas do território; destaca-se a heterogeneidade da agricultura familiar, que apesar do sistema agroalimentar hegemônico, organizado em torno das cadeias longas de produção de leite, suínos e frangos, possibilitou a manutenção de práticas como a produção para o autoconsumo, como a agroindustrialização.

Segundo Berold, Grisel, Schmitz (2007), o agroturismo geralmente associado à agroindústria familiar, tem despertado o interesse de agricultores familiares do Vale do Taquari, que buscam processar parte da produção, agregando valor aos produtos e constituindo um mercado a partir do público urbano, que encontra nessas propriedades espaço de lazer.

Ainda, na perspectiva de valorização dos produtos da agricultura familiar, pode-se observar um aumento da demanda por produtos oriundos dessa agricultura, classificados pelos consumidores urbanos como "produtos da colônia". Essa designação valoriza os produtos agrícolas produzidos nas unidades familiares, como queijos, embutidos de carne suína, frango caipira, hortaliças cultivadas organicamente e mel.

\section{Arranjo Produtivo Local (APL) e a agroindustrialização do Vale do Taquari}

O desenvolvimento local, voltou a ganhar relevância nos últimos anos, em especial a promoção de Arranjos Produtivos Locais (APLs). Estes referem-se à uma forma de aglomeração produtiva de empresas produtoras de bens e serviços afins, que são favorecidas por políticas e ações dos poderes públicos e privados, instituições de pesquisa e centros de tecnologia, e destacam-se por sua capacidade de geração de empregos. Buarque (2006) define, em linhas gerais, desenvolvimento local como um processo endógeno de mobilização das energias sociais em espaços de pequena escala (municípios, localidades, microrregiões) que implementam mudanças capazes de elevar as oportunidades sociais, a viabilidade econômica e as condições de vida da população.

O Estado do Rio Grande do Sul foi pioneiro em criar políticas para Arranjos Produtivos Locais (APLs), quando, no início dos anos 2000, apoiou os sistemas locais de produção (SLPs). Desde então, continua apoiando os APLs, mas foi somente em 2011, ao ser aprovada a Lei n. ${ }^{\circ} 13.839$, que instituiu a Política Estadual de Fomento à Economia da Cooperação, que foi criado o Programa Estadual de Fortalecimento das Cadeias e Arranjos Produtivos Locais e que começou a tomar a forma em que está estruturado atualmente.

Segundo Cassiolato e Lastres (2003), a formação de arranjos e sistemas produtivos locais encontra-se geralmente associada à trajetória histórica de construção de identidades e de formação de vínculos territoriais (regionais e locais), a partir de uma base social, cultural, política e econômica comum. Neste sentido, os 
APLs são mais propícios a desenvolverem-se em ambientes favoráveis à interação, à cooperação e à confiança entre os atores. Neste contexto, a ação de políticas públicas pode contribuir para fomentar e estimular tais processos históricos de longo prazo.

O APL Agroindústria familiar Vale do Taquari, está enquadrado no Programa Estadual de Fortalecimento das Cadeias e APLs desde agosto de 2013, contou inicialmente com 38 agroindústrias cadastradas. Este número foi crescendo gradativamente e em dezembro de 2017, ocorreu a inclusão de mais 8 municípios, totalizando 20 municípios e 85 estabelecimentos.

Entre os produtos agroindustrializados estão açúcar mascavo, melado, rapadura, aguardente, carne e embutidos, banha e torresmo, conservas, doces e geleias, sucos, vinho, nozes, massas congeladas, bolachas, pães, cucas, aipim descascado e congelado, queijos e erva-mate.

\section{Gráfico 1 - Distribuição das Agroindústrias Associadas ao APL Agroindústria por tipo de produção em 2017}

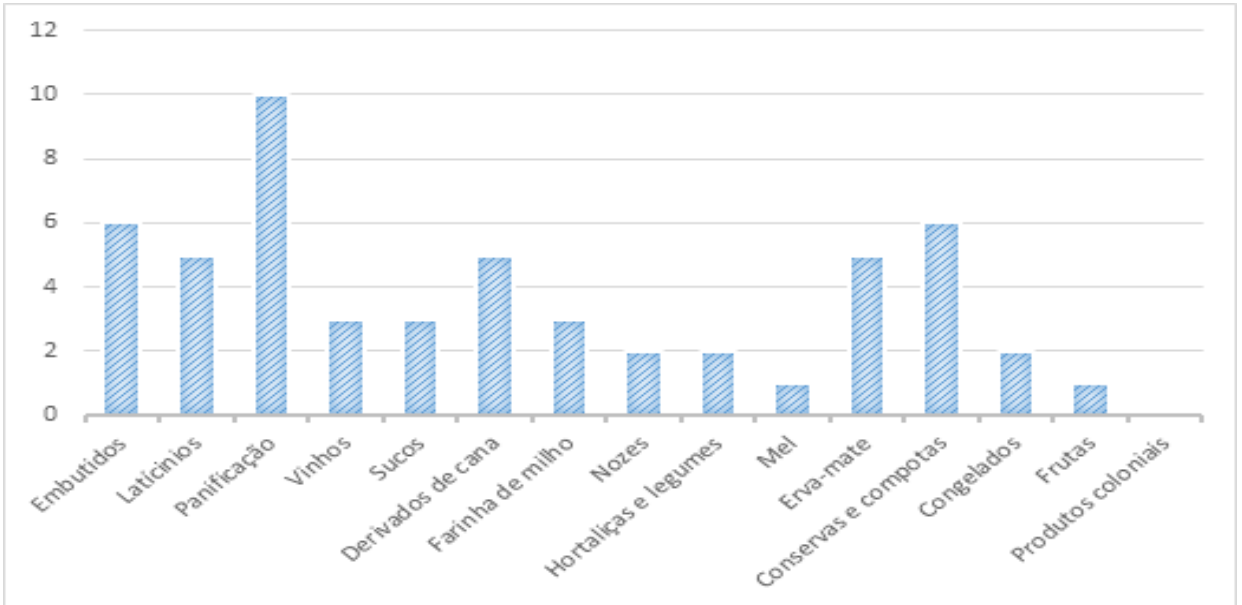

Fonte: elaborado pelos autores, adaptado a partir de APL Agroindústria Vale do Taquari (2017).

Grande parte das agroindústrias associadas ao APL, já existia antes da política pública que instituiu o arranjo, porém destaca-se a capacidade de fomentar o associativismo e a governança, que possibilitou cursos de formação como os de BPF - Boas práticas de fabricação e gestão da propriedade, ofertados pelo SENAR e SEBRAE, além de inúmeras visitas técnicas a diversas regiões do país e uma viagem à Itália. Destaca-se a grande participação feminina entre as agroindústrias participantes, não apenas no processo de produção, mas também na gestão e governança.

No norte do Vale do Taquari, colonizado por imigrantes italianos e alemães, as agroindústrias sempre fizeram parte da dinâmica social, constituindo uma alternativa de renda para famílias de agricultores, possuindo uma grande importância econômica e social. Neste cenário, políticas públicas de apoio e incentivo, como os Arranjos produtivos locais e acesso à credito para aumentar a capacidade investimento dos agricultores, podem potencializar o associativismo, a formação de novas redes sociotecnicas e novos mercados.

A valorização da produção agroindustrial, fruto de políticas públicas de incentivo, a partir dos anos 2000, estimulou a legalização dos estabelecimentos. $O$ 
selo Sabor Gaúcho é uma marca que identifica os produtos com origem na agricultura familiar gaúcha, que participam do Programa Estadual de Agroindústria Familiar (PEAF), agroindústrias que estão com as questões fiscal, sanitária e ambiental em dia, podem solicitar autorização para utilizarem o selo Sabor Gaúcho em seus produtos.

Quanto a fiscalização e enquadramento, a maioria está legalizada através da inspeção da Vigilância sanitária ou enquadrada no SIM (Sistema Municipal de Inspeção), que permite a comercialização apenas dentro do município, ou em casos excepcionais, como as grandes feiras, como a Expointer, cuja participação está regulada por editais. Apesar do número expressivo de estabelecimentos, a maioria dos municípios ainda não possui o SUSAF (Sistema Unificado Estadual de Sanidade Agroindustrial Familiar, Artesanal e de Pequeno Porte), regulamentado pelo Decreto Estadual $n^{\circ} 49340$ de 05 de julho de 2012, que permite aos estabelecimentos registrados nos Serviços de Inspeção Municipais, o comércio em todo o território do estado do Rio Grande do Sul, o que só caberia àqueles registrados na Secretaria da Agricultura, Pecuária e Agronegócio (SEAPA) por meio do Serviço Estadual de Inspeção (CISPOA).

\section{Gráfico 2. Tipo de inspeção das Agroindústrias integrantes do APL Agroindústria Vale do Taquari}

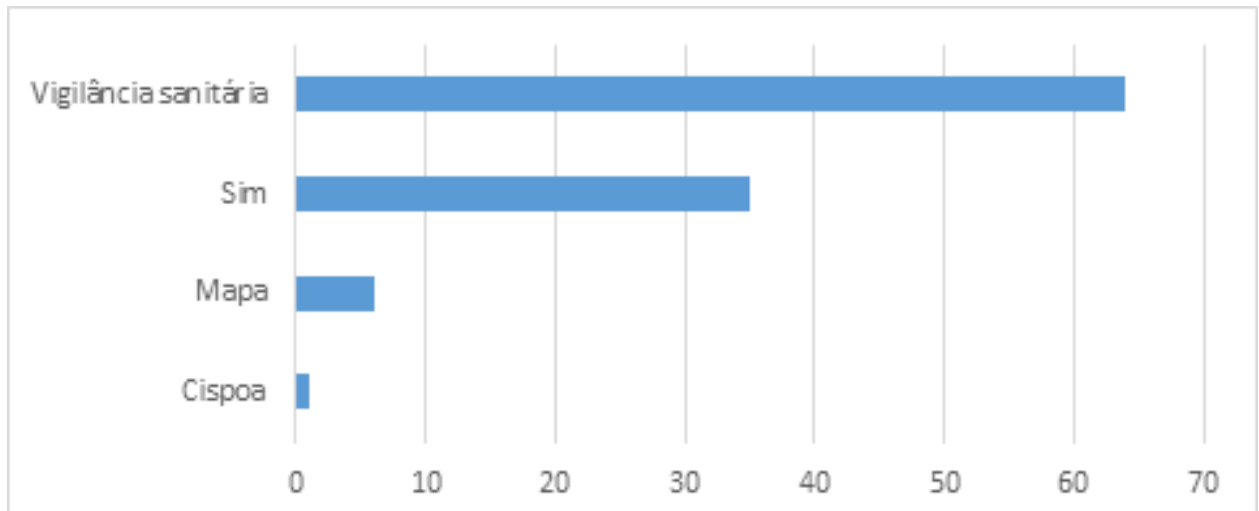

Fonte: Elaborado pelos autores, adaptado a partir de APL Agroindústria Vale do Taquari (2017).

No momento discute-se entre o grupo gestor do APL, o desenvolvimento de um Selo de identificação geográfica, valorizando os produtos das Agroindústrias do Vale do Taquari, que tem como objetivo dar maior visibilidade aos alimentos que são produzidos no território e suas particularidades. O grupo gestor e a AMTURVALES, entidade que promove o turismo, estudam integrar o trabalho das agroindústrias com os roteiros turísticos ligados ao ecoturismo, através de um centro de atendimento ao turista, uma loja com todos os produtos das agroindústrias participantes.

Observa-se a necessidade de dar continuidade ao trabalho de fortalecimento da governança do APL, bem como buscar a ampliação com a adesão de mais agroindústrias. Para fortalecer o trabalho destacam-se as ações: contratação de equipe técnica, um gestor executivo e um auxiliar administrativo; realização de reuniões mensais com a Governança do APL; realização de visitas de mobilização e acompanhamento das agroindústrias e instituições; eventos técnicos de interesse do APL; articulação e apoio à participação das agroindústrias em feiras, como 
expositoras; criação de site do APL; integração com o turismo através da criação de rotas gastronômicas, integradas a roteiros de ecoturismo.

Segundo o Plano Estratégico de Desenvolvimento de Agroindústrias Familiares do Vale do Taquari, APL (2015), o próprio município, onde estão localizadas, é o principal mercado para 90,2\% das agroindústrias entrevistadas e este representa $48,4 \%$ de suas vendas, em média. Outros municípios do Vale do Taquari são o segundo mercado para $62,7 \%$ das agroindústrias entrevistadas e este representa, em média, $36,7 \%$ do total das vendas.

Embora o mercado local seja o majoritário para as agroindústrias do APL, existe uma diversificação nos mercados, pois muitos produtos têm um potencial de expansão muito além do consumo local, como é o caso da erva-mate, das frutas, nozes e produtos não perecíveis, como farinhas e derivados de açúcar. $O$ aprofundamento da diversificação dos mercados também será importante para agroindústria, pois a especialização em produtos naturais, artesanais tem um potencial de crescimento da produção muito superior à capacidade de crescimento do mercado local.

A disponibilidade de recursos naturais, o acesso aos conhecimentos sócio técnicos, suporte da infraestrutura científica e tecnológica e as políticas públicas, aumentam as chances dos empreendimentos. Há uma grande diversidade e qualidade de recursos naturais, solo, clima, luminosidade, a qual oferece inúmeras possibilidades de produção para venda in natura e para industrialização no próprio estabelecimento. Neste campo as possibilidades são imensas, pois a participação da agroindústria familiar na produção da agropecuária ainda é baixa, no entanto, tem forte potencial para crescer.

O Arranjo produtivo, instituído por meio de política pública, exerce papel de agência, que fomenta o associativismo e a organização dos agricultores que estão redescobrindo práticas de produção de alimentos historicamente construídos, como um espaço de manobra e resistência frente a subordinação aos mercados hegemônicos. A estrutura de governança proporciona estímulos a novos circuitos de produção e comercialização, diversificando a agricultura familiar, gerando renda, incentivando a sucessão familiar.

Como já previsto por Maluf (2004), o desenvolvimento dos projetos de agregação de valor às matérias-primas agrícolas e as novas formas de inserção nos mercados ocorrem de forma gradativa, sem romper, imediatamente, as relações comerciais já existentes, como as cadeias integradas de suínos, aves e leite, presentes na maioria das unidades familiares do território.

Neste contexto, as agroindústrias familiares, com práticas legitimadas pela cultura local, como produtoras de alimentos de sabor e qualidade singular, desenvolvem-se paralelamente as cadeias de integração vertical, assimilando em alguma medida os padrões e regras impostos pelos impérios alimentares. A procura por alimentos com características singulares por parte dos consumidores urbanos, vem mudando às práticas de agroindustrialização, agregando novos atributos, como a busca por certificação de origem, certificação orgânica, composição nutricional diferenciada. Considerando as características da agricultura familiar do território, cujas propriedades são de pequeno porte, o processamento da produção agrega valor, gerando renda, aumentando a autonomia, o que serve de estímulo a sucessão rural, constituindo-se uma alternativa à integração agroindustrial. 


\section{Turismo como estratégia de diversificação e criação de novos mercados}

A inserção do turismo no Vale do Taquari enquanto atividade econômica é bastante recente, com a criação da AMTURVALES, em 1990, alguns importantes avanços ocorreram. No início dos anos 90, novas práticas sociais surgem, roteiros gestados por prefeituras como a Rota Germânica emTeutônia, Delícias da Colônia, roteiro que integra os municípios de Estrela, Colinas e Imigrante. Em 1995 é oficializada a criação da AMTURVALES, composta por entidades de iniciativa privada e poder público, tendo como objetivo, planejar e coordenar ações de turismo no território.

Entre as ações desenvolvidas está a organização de materiais de divulgação junto a Secretaria de Turismo do Estado e elaboração de um planejamento estratégico para o turismo, no âmbito de abrangência do Conselho de Desenvolvimento do Vale do Taquari (CODEVAT). O objetivo deste planejamento foi criar um processo participativo que resultou na formulação do Plano turístico do Vale do Taquari e no Turisvale, comitê gestor do turismo no vale. Após os anos 2000, as ações passaram a ser focadas na valorização da diversidade de paisagens e culturas do vale, estimulando a criação devários roteiros:

i. Caminho dos Moinhos - contempla os municípios de Anta Gorda, Arvorezinha, Ilópolis e Putinga. O passeio mostra ao turista admiráveis registros da imigração italiana, do começo do século passado, os moinhos de farinha que resistiram ao tempo e continuam em atividade.

Caminhos da Forqueta - oferece visitação a igrejas, museu, apiário, alambique, café colonial, restaurante, horta orgânica, relógio de chás, compostagem orgânica, trilha e mirante.

ii. Rota da Erva-mate - a Erva-Mate inspirou a formação deste roteiro que é constituída pela união de 10 municípios: Anta Gorda, Arvorezinha, Coqueiro Baixo, Doutor Ricardo, Encantado, Ilópolis, Itapuca, Nova Bréscia, Putinga e Relvado. No percurso de aproximadamente 80 quilômetros, o turista encontra um conjunto de atrativos turísticos acompanhado de belas paisagens naturais emolduradas entre vales e morros, aliado também à saborosa gastronomia italiana e à hospitalidade interiorana, característica de uma comunidade de colonização italiana, mas que também carrega fortemente a identidade do povo gaúcho.

iii. Rota Germânica - conhecida por seus 15 pontos turísticos, 12 em Teutônia e três em Westfália, permite ao turista conhecer um pouco mais da cultura germânica, por meio das tradições que ainda hoje são cultivadas, como a confecção do sapato de pau, símbolo dos dois municípios, além da culinária, arquitetura germânica e belas paisagens.

iv. Rota Turística Trilhas e Memórias - está em formatação com o objetivo de integrar os municípios de Boqueirão do Leão, Canudos do Vale, Cruzeiro do Sul, Forquetinha, Marques de Souza, Progresso, Santa Clara do Sul e Sério. O turista conhece nesta região as marcas das colonizações alemã e italiana, paisagens deslumbrantes por entre os vales e os rios, aliadas à acolhida de um povo simples e hospitaleiro. 
v. Roteiro Encantado - localizado no município de Encantado, o Roteiro consiste num passeio por atrações turísticas, culturais, religiosas, artesanais e históricas de Encantado.

vi. Roteiro Turístico Delícias da Colônia - oferece um tour por pontos turísticos de Estrela, Colinas e Imigrante. Nos passeios, os visitantes contemplam desde as pastagens aos casarios de época, passando por locais que exaltam a gastronomia típica e a hospitalidade interiorana.

vii. Roteiro Turístico Taquari Açoriano - realiza um tour pela cidade de Taquari, município que no ano de 1760 recebeu os primeiros imigrantes provindos do arquipélago dos Açores que iniciaram a colonização do Vale.

viii. Tour por Lajeado - o roteiro consiste num passeio com ônibus aberto por Lajeado, maior cidade do Vale, para conhecer seus pontos turísticos, parques, margens do Rio Taquari e história.

Além destes roteiros, existe o turismo de eventos, que configura uma nova prática social, tornam-se muito comuns na região, como a Expovale (Lajeado), Suinofest (Encantado), Festa de Maio (Teutônia), Expofeira (Estrela) e festas de comemoração de aniversário de municípios e festas de cunho religioso. Com o trabalho desenvolvido, o número de turistas vem crescendo, como se pode observar no gráfico.

\section{Gráfico 3 - Número de turistas que visitaram o Vale do Taquari (2009- 2016)}

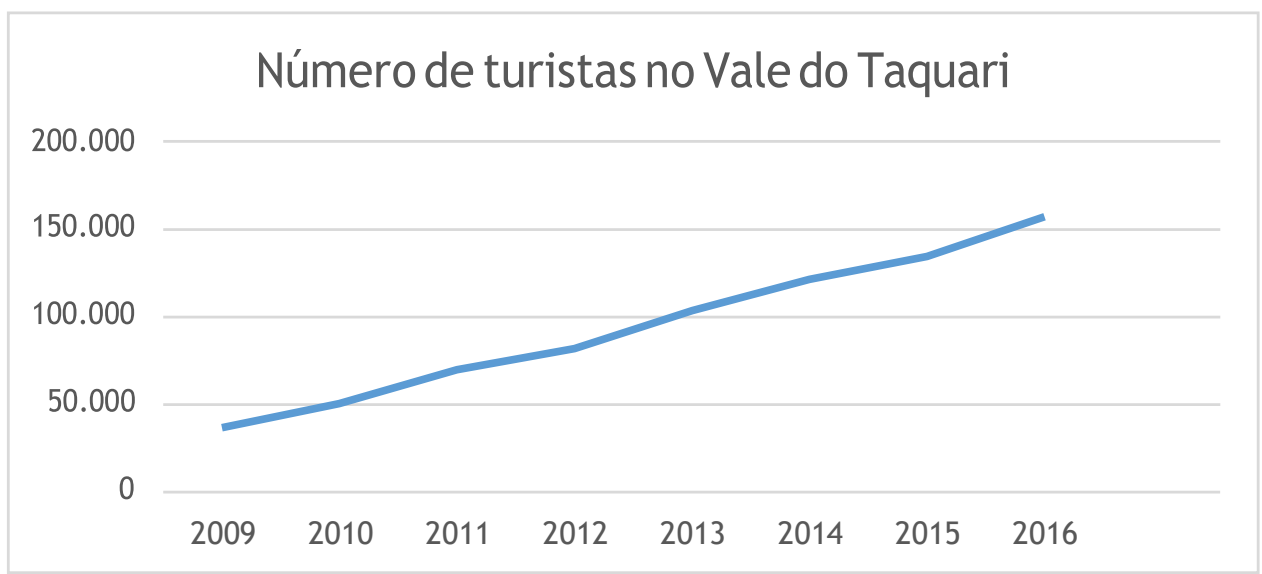

FONTE: Autores (adaptado de AMTURVALES, 2017)

O crescimento do número de turistas leva as instituições como o SEBRAE e a AMTURVALES a apostarem na formação de novos roteiros e grupos. O ecoturismo, 0 turismo rural e o gastronômico são projetos em construção no território.

Com um crescimento continuo do turismo, novas ações estão sendo planejadas pela AMTURVALES, como a realização de cursos de capacitação para organizadores de eventos e demais assuntos relacionados ao turismo e a Reconstrução do Processo Histórico da Erva-mate, a partir da construção do Parque temático da Erva-mate, que conta a história da erva, desde o tempo dos índios até a atualidade, junto ao Parque do Ibama, em Ilópolis. Além das melhorias na sinalização viária e turística, nas principais rodovias que passam pela região. Porém, o grande sonho é o projeto do Trem turístico da Ferrovia do Trigo, cujo roteiro prevê englobar 
sete municípios: Estrela, Colinas, Roca Sales, Muçum, Dois Lajeados, Vespasiano Corrêa e Guaporé, uma distância de 60 km.

Os turistas que embarcarem na locomotiva poderão vivenciar a cultura, gastronomia e atrativos turísticos típicos de cada localidade, a concretização deste roteiro interligaria os diversos roteiros que existem na região. O projeto está aguardando autorização para implantação do empreendimento, entregue na Agência Nacional dos Transportes Terrestres (ANTT), em 2014.

Shove et al. (2012), argumenta que as práticas dependem da integração contínua de, pelo menos, três elementos principais: materiais, competência e significados, observamos que a estrutura turística está se consolidando no território, a competência, "o saber fazer" está em formação, através de capacitação de agricultores e instituições. A medida que este processo de transição ocorre, o caráter simbólico que envolve a prática de receber o turista, vai sendo incorporado a cultura da população do Vale, que possui um grande potencial turístico ainda pouco explorado.

\section{Considerações finais}

A agricultura familiar constitui a base do desenvolvimento econômico e social do Vale do Taquari, a diversidade cultural presente desde a ocupação do território, e a heterogeneidade das práticas alimentares, contribuíram para a construção do conhecimento local acerca dos sistemas de produção, agroindustrialização de alimentos e para a construção da estrutura social que tem no associativismo sua sustentação.

A preocupação com a segurança alimentar dos imigrantes que ocuparam o Vale, fomentou a adoção de práticas como a produção para o autoconsumo, garantindo o acesso à uma variedade de alimentos de origem vegetal e animal, a comercialização dos excedentes foi dando origem a mercados, fortalecidos graças ao sistema cooperativista que alavancou o desenvolvimento. A modernização estimulou a mercantilização da agricultura, que através de práticas de poderes em escalas locais e mundiais, resultou na consolidação de um mercado agroalimentar hegemônico, orientado pela escala, produtividade e distanciamento entre agricultores e consumidores.

A agroindústria familiar é uma estratégia de reprodução social e de desenvolvimento rural importante na agricultura familiar no Vale do Taquari, pois esta é responsável pela fixação das famílias no campo, pela diversificação de atividades produtivas, agregação de valor à produção promovendo novos arranjos sociais e estruturas de governança horizontalizadas. As práticas de agroindustrialização sempre estiveram presentes na história do Vale, resistindo ao processo de modernização, com 215 estabelecimentos cadastrados na Secretaria Estadual de Desenvolvimento Rural em 2017. Políticas públicas de incentivo foram fundamentais para sua regularização e enquadramento às normas sanitárias e organização do sistema produtivo.

A construção e o acesso a novos mercados, a criação e o desenvolvimento de novos produtos e/ou processos produtivos, a formação e a consolidação de novas organizações locais, superam a mera produção de mercadorias desenvolvendo a autonomia dos agricultores familiares, possibilitando a sua reprodução social. A 
qualidade passa a ser fator chave nesse processo e cresce a necessidade de se (re) construir a relação de confiança ente produtores e consumidores fazendo crescer a valorização dos alimentos produzidos localmente e a produção orgânica, agroecológica e artesanal das cadeias curtas, o que permite uma reconexão entre produtores e consumidores, através de Sistemas Agroalimentares Localizados, SIAL, fortemente enraizado no território.

A criação de novos arranjos que facilitem o acesso a alimentos saudáveis como cestas de produtos, grupos de consumo e a integração entre as práticas agroecológicas e agroindustriais, ampliam a oferta de alimentos para o consumidor e agregam valor para $\mathrm{o}$ agricultor. $A$ integração entre as práticas de agroindustrialização com o turismo pode acelerar o processo de transição, relocalizando o sistema agroalimentar, criando novos mercados, com a criação de roteiros que valorizem a gastronomia local, associada à paisagem, ao ecoturismo. A criação de selos de origem e identificação do território está em análise e pode contribuir para a valorização da produção local, agregando valor à produção. A importância da construção territorial, da inovação em produtos e serviços, onde a dimensão territorial constitui uma dimensão essencial de todo processo de inovação, fortemente ancorada em práticas sociais.

O crescimento no número de turistas e a proposição de novos roteiros, novas práticas sociais e a integração entre as práticas, através de novos arranjos materiais e sociais, integrando a paisagem, as práticas alimentares e a cultura do Vale do Taquari constituem um projeto de desenvolvimento rural. A aproximação entre o rural e o urbano, confere maior autonomia aos agricultores, agregando valor à produção e atribuindo novas funcionalidades à propriedade, incorporando novos significados e práticas ao modo de vida dos agricultores familiares.

A heterogeneidade da agricultura familiar do território pode ser observada pela diversidade de práticas e processos de agroindustrialização, que colaboram para a agregação de valor e a relocalização do sistema agroalimentar, reconectando agricultores e consumidores. O resgate das práticas artesanais de produção de alimentos, adequando-as a legislação vigente, construindo novos arranjos de práticas e padrões de qualidade, que atendam ao consumidor e possibilitem a autonomia dos agricultores frente aos mercados, constitui-se uma inovação social, uma estratégia para o desenvolvimento rural no território.

\section{Referências}

AHLERT, L.; GEDOZ, S. T. Povoamento e desenvolvimento econômico na região do Vale do Taquari, Rio Grande do Sul - 1822 a 1930. Revista Estudo \& Debate, Lajeado, v. 8, n. 1, p. 49-91, 2001

APLAGROINDÙSTRIAVALEDOTAQUARI.Disponívelem: http://www.aplvaledotaquari.com.br/agroindustrias/agroindustrias-participantes. Acesso em 25 jun. 2017.

ASSOCIAÇÃO DOS MUNICÍPIOS DE TURISMO DA REGIÃO DOS VALES AMTURVALES.Disponívelem:http://www.amturvales.com.br/roteiros/, acesso em: 30 de nov. 2017. 
BEROLD, Leonardo; GRISEL Pierre-Nicolas , SCHMITZ José Antônio; Evolução e diferenciação da agricultura no Vale do Taquari: um estudo comparado de dois sistemas agrários. In: MENASCHE, Renata(Org)Agricultura familiar à mesa: Saberes e práticas da alimentação no Vale do Taquari, Ed UFRGS, 2007. BUARQUE, C.S. Construindo o desenvolvimento local sustentável. São Paulo: Garamond, 2006.

CASSIOLATO, J. E.; LASTRES, M. H. O foco em arranjos produtivos e inovativos locais de micro e pequenas empresas. In: LASTRES, M. H.; CASSIOLATO, J. E.; MACIEL, M. L. (Org.). Pequenas empresas: cooperação e desenvolvimento local. Rio de Janeiro: Relume Dumará, 2003. p. 21-34.

CIRAD. Systèmes agroalimentaires localisés: organisations, innovations et développement local. Montpellier: Cirad, 1996. CODEVAT. Plano estratégico de desenvolvimento - PED- do APL Agroindústrias Familiares do Vale do Taquari, 2015, disponível em: <http://codevat.org.br/uploads/documento/2076/1_PLANO_PED_AFVT.pdf >. Acesso em: 12 nov. 2017.

CRUZ, Fabiana T.; SCHNEIDER, Sérgio. Qualidade dos alimentos, escalas de produção e valorização de produtos tradicionais. Rev. Bras. de Agroecologia, v. 5, n. 2, p. 22-38, 2010

GIDDENS, Anthony. A constituição da sociedade. São Paulo: Martins Fontes, 1984.

INSTITUTO BRASILEIRO DE GEOGRAFIA E ESTATÍSTICA -IBGE. Atlas do

Censo demográfico 2010. Rio de Janeiro: IBGE 2013, disponível em: <https://ww2.ibge.gov.br/home/estatistica/populacao/cens02010/default_atlas.s htm,>. Acesso em: 23 jun. 2017.

INSTITUTO BRASILEIRO DE GEOGRAFIA E ESTATÍSTICA -IBGE. Índice de produção Agropecuária Municipal. 2015. Disponível em:

<https://www.ibge.gov.br>. Acesso em: 28 out. 2017.

INSTITUTO BRASILEIRO DE GEOGRAFIA E ESTATÍSTICA IBGE- Relatórios Metodológicos. Produto interno bruto dos municípios. Rio de Janeiro: IBGE, 2016.Disponível em: https://www.ibge.gov.br/estatisticasnovoportal/economicas/contas-nacionais/9088-produto-interno-bruto-dosmunicipios.html,>. Acesso em: 23 jun. 2017.

KOLCHINSKI, E., ZANETTI, C., BIONDO, E. and OLIVEIRA, L. Plano territorial de desenvolvimento rural sustentável do Vale do Taquari. 1 ed. Encantado: UERGS, 50 p, 2017.

MALUF, R. Mercados agroalimentares e a agricultura familiar no Brasil: agregação de valor, cadeias integradas e circuitos regionais. Ensaios FEE, Porto Alegre, v. 25, n. 1, p. 299-322, abr. 2004. 
MARSDEN, T.; BANKS, J.; BRISTOW, G. Food supply chain approaches: exploring their role in rural development. Sociologia Ruralis, v. 40, n. 4, p. 424-438, 2000.

MENASCHE, R. Saberes e sabores da colônia: alimentação e cultura como abordagem para o estudo do rural. Porto Alegre: Editora da UFRGS, 2015. MIOR, L. C. Agricultores familiares, agroindústrias e rede de desenvolvimento rural. Chapecó: Argos, 2005.

MUCHNIK, J. Les systèmes agroalimentaires localisés: intérêt, approche, interrogations. In: Colloque Syal. Montpellier, 2002.

OBSERVATÓRIO BRASILEIRO DE ARRANJOS PRODUTIVOS LOCAIS.

Disponível em: http://portalapl.ibict.br/. Acesso em: jun. 2017.

PECQUEUR, B. Qualité et développement territorial: I'hypothèse du panier de biens et de services territorialisés. Economie Rurale, 261, 2001.

PECQUEUR, Bernard. A guinada territorial da economia global. Política e Sociedade: Revista de Sociologia Política, PPSP UFSC, 2009. Disponível em:

http://www.periodicos.ufsc.br/index.php/politica/article/view/11615/10955 Acesso em: 05 jun. 2016.

RELATÓRIO DECENAL ARRANJOS PRODUTIVOS LOCAIS. APL

Agroindústria Familiar Vale do Taquari. Disponível em:

<http://www.sdect.rs.gov.br/upload/arquivos/carga20170526/04092652-

1418296733-relat-c3-b3rio-20decenal-20apl-20agroind-c3-bastria-2ofamiliar-20do20vale-20do-2otaquari.pdf $>$. Acesso em: 12 jan. 2018.

RIO GRANDE DO SUL, Lei 13839/2011; Institui a Política Estadual de Fomento à Economia da Cooperação Disponível em:

http://www.al.rs.gov.br/FileRepository/repLegisComp/Lei\%20n\%C2\%BA\%2013.

839.pdf. Acesso em: 10 mar. 2018.

RIO GRANDE DO SUL, Instrução Normativa N 02/2013; Aprova os Requisitos para Adesão dos Municípios ao Sistema Unificado Estadual de Sanidade Agroindustrial Familiar, Artesanal e de Pequeno Porte-SUSAF-RS. 2013.

RIO GRANDE DO SUL, Decreto N 49340 DE 05/07/2012; dispõe sobre o Sistema Unificado Estadual de Sanidade Agroindustrial Familiar, Artesanal e de Pequeno Porte - SUSAF-RS. Disponível em:

https://www.legisweb.com.br/legislacao/?id=243083. Acesso em 10 de março de 2018.

SCHATZKI, Theodore. R. Introduction. In: SCHATZKI, T. R.; KNORR, Cetina, K.; SAVIGNY, E. von (Ed.). The practice turn in contemporary theory.

London: Routledge, 2001, p. 1-14. 
. The sites of organizations. Organization Studies, v. 26, n. 3, 2005, p. 465-

484.

SCHNEIDER, Sérgio. A abordagem territorial do desenvolvimento rural e suas articulações externas. Sociologias; Porto Alegre, ano 6, n 11, jan/jun,p. 88- 125, 2004.

SHOVE, Elizabeth; CARMONA, KELLY, Chris \& Michael P. Theories of practice and public health: understanding (un)healthy practices, Critical Public Health. 2012.

SONNINO, Renata; MARSDEN, Terry. Além da linha divisória: repensando relações entre redes alimentares alternativas e convencionais na Europa. In: GAZOLLA, M; SCHNEIDER, S(Org.) Cadeias curtas e redes agroalimentares alternativas: negócios e mercados da agricultura familiar

- Porto Alegre: Editora da UFRGS, 2017.

WOORTMANN, Klaas; WOORTMANN, Ellen F. O trabalho da terra: a lógica e a simbólica da lavoura camponesa. Brasília: EdUnB, 1997.

Mirian Fabiane Dickel Strate. Mestre em Desenvolvimento Rural pela UFRGS (2018).

Marcelo Conterato. Professor Associado I da Universidade Federal do Rio Grande do Sul, vinculado ao Departamento de Economia e Relações Internacionais (DERI) $e$ ao Programa de Pós-Graduação em Desenvolvimento Rural (PGDR). marceloconterato.ufrgs@gmail.com

\section{Submetido em: 30/10/2018 Aprovado em: 27/12/2018}

Como citar: STRATE, Mirian Fabiane Dickel; CONTERATO, Marcelo Antonio. Práticas de agroindustrialização e arranjos produtivos locais como estratégia de diversificar e fortalecer a agricultura familiar no Rio Grande do Sul. Redes, Santa Cruz do Sul, v. 24, n. 1, p. 227-245, jan. 2019. ISSN 1982-6745. Disponível em: https://doi.org/10.17058/redes.v24i1.13052. 